\title{
Lessons from Theranos: Changing Narratives of Individual Ethics in Science and Engineering
}

\author{
MELANIE JESKE ${ }^{1}$ \\ UNIVERSITY OF CALIFORNIA, SAN FRANCISCO
}

\begin{abstract}
The meteoric ascent and equally dramatic fall of Theranos has been covered prolifically in the media. Presented as an ambitious inventor gone rogue, the discursive construction of the Theranos scandal in popular media and in the biomedical community reifies tired narratives of the role of ethics in science and engineering fields more generally: narratives that emphasizes individual integrity and common sense rather than the structures and norms that leave scientists and engineers vulnerable to ethical quandaries. In this short critical engagement, I argue that the ways Theranos has been captured obscures important conversations about ethics in bioscience and biotechnology, both in the private sector and in university spaces. I call for STS scholars to engage with scientists and engineers to imagine ways to structurally embed ethics and justice in future technoscientific endeavors.
\end{abstract}

\section{Keywords}

ethics; bioscience; bioengineering; university-industry relations; governance

By now, the public has been introduced to the recent Theranos scandal that rocked biotech and innovation-obsessed Silicon Valley. Theranos, now defunct, was a startup company founded by a young white woman, Stanford drop-out entrepreneur, Elizabeth Holmes. The company claimed to have developed a novel biomedical testing device, "the Edison," that could run hundreds of

\footnotetext{
${ }^{1}$ Melanie Jeske, Email: mel.jeske@ucsf.edu

Copyright (C) 2020 (Melanie Jeske). Licensed under the Creative Commons Attribution Non-commercial No Derivatives (by-nc-nd). Available at estsjournal.org.
} 
diagnostic tests using only a single drop of blood. ${ }^{2}$ As the saga unfolded, we learned how Holmes enticed venture capitalists of well-known firms in Silicon Valley, garnered the support of "powerful men" (e.g., James Mattis, George Shultz, Henry Kissinger), as well as attention from tech business reporters from The New Yorker, Wired, and the Wall Street Journal. Ultimately, however, Holmes was "caught" lying to investors and potential end users about the device's functionality. Holmes and her business partner, Ramesh (Sunny) Balwani, are facing charges of wire fraud and conspiracy to commit wire fraud and are set to stand trial in late 2020. As I write this article in the summer of 2020, Carreyrou's 2018 journalistic account, Bad Blood: Secrets and Lies in a Silicon Valley Start Up, became a best seller, several podcasts have been produced, and HBO released a documentary about the scandal. ${ }^{3}$ A major motion picture adaptation of Carreyrou's book is in the works, with Jennifer Lawrence set to portray Elizabeth Holmes. Presented by the media as an inventor gone rogue, Theranos seems exceptional-a situation in which a "good," honest scientist or engineer can't fathom finding oneself.

I come to this case as a sociologist studying the social worlds of academic biomedical engineers. ${ }^{4}$ In these spaces I have observed how the Theranos scandal has become a trope in conversations about ethics. Frequently, in scientific conference settings, informal conversation, and in the classroom, Theranos (and Holmes) is referenced as a cautionary tale of over promising and under delivering when developing innovative biomedical technologies. On a few occasions, biomedical engineers referenced trying to build similar devices themselves and failing. Or, as one

\footnotetext{
2 This was how the device was marketed. However, it never achieved these goals: consumers who had their blood drawn through Theranos clinics often had to have a regular blood draw (i.e. more than a single drop of blood). Samples were subsequently analyzed using commercially available devices used in Theranos labs or outsourced to commercial labs.

3 These portrayals spotlight Holmes' quirky characteristics--her lack of blinking, trained deep voice, emulation of successful tech men (e.g. her attire choice of a black turtleneck, a nod to Steve Jobs of Apple), as well as her "deceitful" nature. Though not the focus of this essay, the Theranos case and the scrutiny of Holmes is highly gendered. Carreyrou's account, for instance, both downplays Holmes' own discussion of sexism she faced in the industry as a distraction tactic and closes his book questioning whether Holmes is a sociopath.

${ }^{4}$ Bioengineering and biomedical engineering are often used interchangeably in the field. My informants often describe difference in terminology for university departments as depending on the department founders, and their training in particular fields, but not having much impact on their work. Some university departments have clarified what they see as the difference between bioengineering and biomedical engineering, particularly as they seek to offer degree programs in separate subfields (see, for example, Pennsylvania State University explanation of the difference between biomedical and biological engineering).
} 
professor at a large public research university told his undergraduate class, he had given up on a similar idea precisely because he had heard "someone else was already making it."

By and large, in these communities and in the broader media, Theranos has been talked about as an entrepreneur who went too far, falling into the stereotypical "bad apple" narrative that is all too pervasive in science and engineering settings. The focus of Carreyrou and others in the media suggests that individual psychology is what should be scrutinized rather than the infrastructure of science and technology development. These individualistic accounts enable the Theranos scandal to fit into broader cultural narratives about science and technology and the limited role of ethics in these fields. It is the individual who is at fault, not the broader system, that is, the norms and incentive structures that leave scientists and engineers vulnerable to ethical predicaments. This atomized framing amplifies notions of "common sense" and "good" scientists: if scientists are just honest researchers who do the right thing, then they (and we, the public) have nothing to worry about it. The professor's takeaway from the scandal for his students was "Don't lie." But this narrative is dangerous. It tactfully skirts meaningful and tough conversations about the embeddedness of ethics in daily scientific practice, particularly in the bioscience and biotechnology sector that has evolved over the past fifty years-a sector in which academic researchers are encouraged to engage in commercialization, and where industry interests are embedded in research settings.

As STS scholars it is critical that we change this conversation by scrutinizing and illuminating the norms and social structures that enable these actions, and that we develop toolkits that meet these challenges and change the narrative. While the Theranos case played out in the private sector, the concerns it highlights increasingly matter beyond industry settings, particularly in a moment where boundaries between university and industry are, in some fields like bioscience and biotechnology, disintegrating. Among others, STS scholars such as Daniel Kleinman, Elizabeth Popp-Berman, and Steve Hoffman have discussed how career academics are increasingly called upon to straddle university-industry positions, finding opportunities for their technologies and novel discoveries in the private sector. ${ }^{5}$ In these endeavors, scientists and engineers intimately interface with investors and industry representatives who often have little technical knowledge, presenting thorny ethical challenges for ill-prepared researchers to navigate. As one academic bioengineer speaking on a commercialization panel at a scientific

\footnotetext{
${ }^{5}$ Many academic bioengineers and their students aspire to launch start-ups of their own and to collaborate with industry either as their main career or in addition to holding academic appointments; universities and government agencies support and encourage researchers to develop the market potential of their innovations and discoveries. For many bioengineers in my study, commercializing academic research is seen as a social good, and the primary way to realize the "full potential" of their research (Jeske, forthcoming).
} 
conference I observed put it, "It's on us" to know where the line is between pitching the product and knowing when you're promising more than can realistically be delivered. This sentiment alludes to the vagueness of what an ethical code looks like in the biosciences, and a failure to recognize the structural conditions that enable such missteps to happen.

Allowing Theranos to become shorthand, like other ethical transgressions that have become tropes in biomedical research, enables a glossing over of a conversation around the structural problems that present dangers in our current moment of biomedical research and knowledge production. As commercialization has become a goal in academic settings, the practices necessary in industry - that is, the hype, promissory nature, and secrecy for the sake of intellectual property protection-also become requisite for successful academic entrepreneurialism. As STS scholars with deep knowledge and toolkits for tackling these challenges, we now have an opportunity to engage in meaningful dialogue with scientists, engineers, and university administrators about how the analytical tools of STS coupled with a strong justice framework, as discussed by Laura Mamo \& Jennifer Fishman, can play a role in technoscience projects of the future.

Current STS approaches that engage technical experts developing new technologies alongside communities impacted by such developments work well for integration in technoscientific projects in which there is an identifiable population or community (identity based and/or place based). Here I am thinking of participatory engagement efforts in which community members are able to shape regulation and policy, such as those put forward in recent environmental justice scholarship of Barbara Allen, Gwen Ottinger, and David Pellow. Similarly, sociotechnical integration research of Erik Fisher, Lennifer Richter and colleagues, as well as anticipatory governance frameworks developed by David Guston, have demonstrated how embedded social scientists and humanists can interact with technical experts to explicitly incorporate social values and considerations. These approaches can be successful where relevant stakeholders and communities can be identified and engaged, and where the technoscientific project is place-based. And within biomedicine, particularly in genomics and precision medicine, scholars like Nanibaa' Garrison and Jenny Reardon have pointed to frameworks for justice in which populations have the capacity to shape their participation in biomedical research as well as the design and governance of research projects. While engaging communities and stakeholders has shown some success, we also must consider if and when these groups have meaningful power-not only to shape the agenda, but also to say "no", as scholars such as Ruha Benjamin have discussed. As Alondra Nelson recently quoted in her call for a "braver bioethics," in his 2003 testimony on the social implications of nanotechnology, Langdon Winner said of bioethics 
that "the field of bioethics ... has a great deal to say about many fascinating things, but people in this profession rarely say no." STS scholars typically offer a more critical perspective than embedded ethics scholars might, but, even so, we must continue to develop strategies to get through to our audiences, including scientists, engineers, funders, and university administrators, such that we are not only able to shape technoscientific projects but also to change individualized notions of ethics and "good" scientific practice.

In the development of novel biotechnologies that become part of the infrastructure of laboratories as tools (e.g. in vitro diagnostics), we face different challenges. There is often a less clear community or group to engage; while a "market need" and "potential user" may be identified, these are often entities with power: contract research organizations, healthcare systems, pharmaceutical companies, laboratory staff, and clinicians. The people invoked and implicated in the use of these technologies-that is, the "suppliers" of the cells, DNA, blood-are perceived as so far removed from the development of a technology that it becomes easy to say that the product isn't ready for an ethical or social investigation, or worse, that it doesn't need one-both common sentiments in my fieldwork and interviews with bioengineers.

What I am suggesting here is that our conceptual categories and methods may be too limited, if we are only invited to step in where there are pre-identified, clear "ethical issues" surrounding an emergent technology or where there are specific and obvious stakeholders and communities that should be engaged. To embed a justice framework in our approach to technoscience requires that we look beyond the cases in which there are clear populations and communities being (or potentially) harmed and expand ethics concepts beyond the individual-not just in the sense of the individual researchers, but also project by project, technology by technology, sector by sector. This parsing contributes to the challenge of structural change, especially as public-private entanglements have become more intricate and pervasive, and where technoscientific imaginaries fail to encompass social considerations.

The framing of the Theranos scandal exemplifies the problems with the boiled-down ethics approach in science and engineering more generally: one in which we allow the common sense of an elite group to define standard practice, to decide what count as ethical concerns in science, and to exempt ethics from day-to-day research practices. For too long ethics have been regarded as external to the core of science and engineering, something that gets in the way and slows down scientific innovation, and can be regarded as an afterthought. Through its reactive routinization, namely in the form of online trainings, ethics in science and engineering becomes just another hoop to jump through. As Laurel Smith-Doerr found, online ethics training is unlikely to be meaningful to life scientists, and may actually discourage them from taking ethics 
seriously. And as Kelly Joyce and colleagues discussed in a recent critical engagement, the various mechanisms through which scientists and engineers are trained to think about ethics are often just ways to "check the box."

As the Theranos case continues to play out in the courts and in the media, it offers an opportunity to change the narrative. Let's use it to engage in dialogue with scientists, engineers, and entrepreneurs about how we can create a governance framework that brings justice into the center of science and engineering practice and stops placing the onus of integrity and ethics on individual actors and actions alone.

\section{Author Biography}

Melanie Jeske is a doctoral candidate in sociology at the University of California, San Francisco. A medical sociologist and STS scholar, her research explores the social, political and ethical dimensions of knowledge systems, emergent biotechnologies, and biomedical expertise. Melanie's work can be found in journals including BioSocieties, Social Science E Medicine, and Engaging Science, Technology, and Society.

\section{Acknowledgements}

I would like to express my appreciation to colleagues at UCSF who commented on earlier versions of this article, as well as Kelly Joyce, Laura Mamo, and Emily Vasquez. I thank ESTS editors Daniel Kleinman and Katie Vann, and the anonymous reviewer for their insightful comments. 